\section{AS POLÍTICAS PÚBLICAS DE EDUCAÇÃO: A PERCEPÇÃO DOS DOCENTES DE EDUCAÇÃO FÍSICA}

\author{
PUBLIC EDUCATION POLICIES: PHYSICAL EDUCATION TEACHERS'S \\ PERCEPTION
}

\author{
LAS POLITICAS PÚBLICAS DE EDUCACIÓN: LA PERCEPCIÓN DE LOS \\ DOCENTES DE EDUCACIÓN FÍSICA
}

Vera Regina Oliveira Diehl*, Vicente Molina Neto*, Lisandra Oliveira e Silva*
Palavras chave: Política pública. Educação. Prática do docente. Educação Física.

\begin{abstract}
Resumo: O presente artigo é parte de uma pesquisa que objetivou compreender de que modo os docentes de Educação Física participam, percebem e experienciam as Políticas Públicas em Educação na escola e no trabalho docente. Trata-se de uma etnografia educativa em duas escolas públicas da cidade de Porto Alegre. $O$ estudo evidencia que 0 trabalho docente no cotidiano pedagógico das escolas pode ser pensado enquanto manifestação concreta de uma Política Pública de Educação que é interpretada e recriada pelo professorado de Educação Física.
\end{abstract}

Keywords:

Public Policy.

Education.

Faculty practice.

Physical Education.

Palabras clave: Política Pública. Educación. Práctica del docente. Educación Física.
Abstract: This article is part of a study aimed at understanding how Physical Education teachers participate, perceive and experience Public Policies in Education at school and in their work. It is an educational ethnographic study conducted in two public schools in the city of Porto Alegre. The study shows that teachers' work in daily pedagogical life at schools can be thought of as a concrete expression of a Public Education Policy that is interpreted and recreated by Physical Education teachers.

Resumen: El presente artículo es parte de una investigación que busca comprender de qué modo los docentes de Educación Física participan, perciben y experimentan las Políticas Públicas en Educación en la escuela y en el trabajo docente. Se trata de una etnografía educativa en dos escuelas públicas de la ciudad de Porto Alegre. El estudio pone en evidencia que el trabajo docente en el cotidiano pedagógico de las escuelas puede ser pensado como manifestación concreta de una Política Pública de Educación que es interpretada y recreada por el profesorado de Educación Física.
*Universidade Federal do Rio Grande do Sul. Porto Alegre, RS, Brasil. E-mail: veradiehl13@gmail.com; vicente.neto@ufrgs.br; lisgba@yahoo.com.br

Recebido em: 13-11-2018 Aprovado em: 02-05-2019 Publicado em: 10-06-2019

DOI: https://doi.org/10.22456/1982-8918.88121 (c) (1) () Licence 


\section{CONSIDERAÇÕES INICIAIS}

Este artigo é parte de uma investigação em que analisamos e discutimos as percepções dos docentes de Educação Física (EF) sobre as experiências vivenciadas no contexto das Políticas Públicas de Educação implantadas e implementadas na Rede Municipal de Ensino de Porto Alegre (RME/POA). Sendo assim, apresentamos as percepções dos docentes de Educação Física sobre a Política Pública de Educação na RME/POA.

Procuramos compreender de que modo os docentes de Educação Física percebem, participam e experienciam as Políticas Públicas de Educação no cotidiano pedagógico da escola e no trabalho docente 1 . Para tanto, analisamos a efetivação das propostas presentes no Plano Nacional de Educação (Lei no 13.005/14), Plano Municipal de Educação (Lei no 11.858/2015) (PREFEITURA MUNICIPAL DE PORTO ALEGRE, 2015) e o trabalho docente do professorado de Educação Física no contexto de ação, a partir de uma etnografia educativa em duas escolas públicas da cidade de Porto Alegre. Os procedimentos para obtenção das informações foram: observações, diário de campo, análise documental, questionário e entrevistas semiestruturadas realizadas com docentes de Educação Física.

Apresentamos, de forma articulada, a revisão bibliográfica, fundamentada em teóricos que, a nosso ver, são fundamentais para a compreensão e análise das Políticas Públicas de Educação. Para entender as Políticas Públicas de Educação do município de Porto Alegre foi necessário analisar o contexto mais amplo, ou seja, o macro e microcontexto. Desse modo, procuramos as contribuições da abordagem do "ciclo de políticas" formulada pelo sociólogo Stephen Ball e colaboradores. Segundo Mainardes (2006, p. 49), essa abordagem enfatiza "os processos micropolíticos e a ação dos profissionais que lidam com as políticas no nível local e indica a necessidade de se articularem os processos macro e micro na análise de políticas educacionais". Entendemos que essa abordagem apresenta grande contribuição, possibilitando a realização de análise das políticas educacionais.

Para compreender de que modo os docentes de Educação Física da Rede Municipal de Ensino de Porto Alegre percebem, participam e experienciam as Políticas Públicas de Educação no cotidiano pedagógico da escola e no trabalho docente, analisamos, inicialmente, as alterações políticas ${ }^{2}$ que vêm sendo introduzidas no atual sistema educativo e que têm contribuído para modificar a vida das instituições escolares, do trabalho docente e da própria educação enquanto projeto coletivo. Acreditamos que essas alterações advêm da necessidade de adequar a escola às exigências do contexto socioeconômico mundial, visto que a educação detém um papel fundamental, tanto do ponto de vista econômico, quanto do social, político e cultural.

\section{POLÍTICAS EDUCACIONAIS COMO AÇÃO PÚBLICA}

Para compreender as Políticas Públicas de Educação do município de Porto Alegre, analisamos o contexto de ação educacional, a partir das contribuições da abordagem do "ciclo

\footnotetext{
1 Entendemos que as experiências se configuram como um elemento estruturante do trabalho docente no contexto escolar. Sendo assim, compreendemos a experiência na perspectiva da práxis na medida em que as reflexões dos docentes consideram os elementos de sua ação, reorganizando, a partir de um conjunto de conceitos teóricos, por meio do diálogo entre a razão e realidade, como possibilidade de provocar mudanças no trabalho docente.

2 Entre as alterações políticas está a redução de uma hora aula semanal - tempo pedagógico - do Componente Curricular Educação Física no 3ำ ciclo do Ensino Fundamental (PREFEITURA. SMED, 2015).
} 
de políticas" formulada pelo sociólogo Stephen Ball e colaboradores que, segundo Mainardes (2006, p. 48), constitui uma referência para a análise crítica da trajetória de programas e políticas educacionais e sociais, desde sua "[...] formulação inicial até a sua implementação no contexto da prática e seus efeitos". Para Mainardes (2006, p. 47), o "ciclo de políticas" proposto por Ball se repete continuamente, sendo constituído por cinco contextos: "contexto de influência, contexto da produção de texto, contexto da prática, contexto dos resultados/efeitos e contexto de estratégia política".

A abordagem do ciclo de políticas contribui como um referencial analítico que ajuda a entender os aspectos que envolvem o atual cenário no qual estão inseridas as Políticas Públicas de Educação no Brasil. Essa abordagem, conforme Mainardes (2006, p. 55), contribui para a análise de políticas educacionais, "uma vez que o processo político é entendido como multifacetado e dialético, necessitando articular as perspectivas macro e micro". 0 autor destaca, ainda, "a natureza complexa e controversa da política educacional, que enfatiza os processos micropolíticos e a ação dos profissionais que lidam com as políticas no nível local e indica a necessidade de se articularem os processos macro e micro na análise de políticas educacionais" (p. 49).

Sendo assim, essa abordagem possibilita compreender e visualizar o processo polêmico e de disputa na elaboração e aprovação da Lei no 13.005/14, Plano Nacional de Educação (PNE-2014/2024), (BRASIL, 2014). Esse processo se torna visível nas relações entre ações de participação da sociedade civil, a partir da realização da Conferência Nacional da Educação e Governo Federal, disputando a incorporação de suas propostas ao PNE-2014/2024. Os recursos para garantir mais investimento para a educação e destinação das verbas públicas exclusivamente nas instituições públicas de ensino, foram um dos campos de disputa.

A Política Pública de Educação, que é uma Política de Estado em curso no Brasil, reúne ações e programas ${ }^{3}$ que vêm se materializando a partir do Plano de Desenvolvimento da Educação (PDE) ${ }^{4}$. Entre as ações previstas no PDE, encontra-se o Plano de Metas Compromisso Todos pela Educação, cujo objetivo é a melhoria da qualidade da educação básica no país. Os indicadores de aferição da melhoria da qualidade educacional têm como base o Índice de Desenvolvimento da Educação Básica (IDEB) ${ }^{5}$. O IDEB se constitui em um instrumento para acompanhamento das metas de qualidade do PDE para a educação básica. O PNE-2014/2024 estabelece uma meta para promover a melhoria do fluxo escolar e da aprendizagem de maneira a alcançar as médias nacionais para o IDEB ${ }^{6}$ (BRASIL, 2014).

O mesmo processo polêmico e de disputa ocorreu na cidade de Porto Alegre. Apesar dos pronunciamentos e manifestações de grupos religiosos, movimentos sociais e entidades educacionais, a diretriz com alusão à igualdade de gênero foi excluída da versão original do Plano Municipal de Educação (PME) ${ }^{7}$ apresentada para apreciação da Câmara Municipal.

\footnotetext{
3 Plano de Metas Compromisso Todos pela Educação, Plano de Ações Articuladas, Programa Dinheiro Direto na Escola, entre outros.

4 Em 2007, foi lançado pelo MEC o Plano de Desenvolvimento da Educação (PDE) (BRASIL, 2008). O PDE se apresenta como um Plano que estabelece ações de implementação de políticas de melhoria da qualidade da educação, sobretudo da educação básica pública. Disponivel em : http://portal.mec.gov.br. Acesso em: 2 maio 2019.

5 Avalia o desempenho dos estudantes em provas realizadas pelo Sistema de Avaliação da Educação Básica, sendo um indicador constituído pela Prova Brasil e pelo fluxo escolar (aprovação e evasão). Foi desenvolvido para ser um indicador de qualidade que resume informações de desempenho em exames padronizados com informações sobre rendimento escolar. É realizado pelo Instituto Nacional de Estudos e Pesquisas Educacionais Anísio Teixeira (INEP) a cada dois anos.

6 Para obter maiores informações a respeito das médias nacionais para o IDEB, consultar tabela na página quatro da Lei $\mathrm{n}^{\circ} 13.005 / 2014$.

7 O projeto do PME foi aprovado pela Câmara Municipal de Porto Alegre e sancionado pelo Prefeito Municipal, transformando-o na Lei nº 11.858 , de 25 de junho de 2015
} 
Para analisar e discutirmos as Políticas Públicas de Educação vivenciadas pelos docentes de Educação Física na RME/POA é necessário considerar as mudanças ocorridas na organização da escola, especialmente, da Educação Física no currículo escolar, como o fato de a RME/POA ter protagonizado uma Política Pública de Educação denominada de Escola Cidadã ${ }^{8}$ comprometida com princípios da educação crítica (APPLE; AU; GANDIN, 2011) e experienciado uma nova mudança na Administração Municipal, a partir de $2005^{\circ}$, permanecendo até 2016. Embora a Proposta Político Pedagógica da Escola Cidadã enquanto Política Pública de Educação não tenha sido formalmente extinta, esse Projeto Educacional vem sendo progressivamente alterado. Desse modo, entendemos que para pesquisar a RME/POA, se faz necessário analisar como o professorado de Educação Física percebe e experiencia na escola e no trabalho docente a continuidade e descontinuidade da Política Pública de Educação na atual gestão municipal. Cabe mencionar que, para Azevedo, Rodrigues e Curço (2010, p. 13), o Projeto Escola Cidadã de Porto Alegre sofreu descontinuidades, não se constituindo mais como Política Pública de Educação. "Sua continuidade depende do enraizamento que alcançou em algumas escolas, onde as mudanças atingiram patamares irreversíveis".

Analisamos, ainda, algumas alterações políticas que vêm sendo introduzidas, atualmente, na RME/POA e como têm contribuído para modificar o cotidiano pedagógico das escolas e a própria educação enquanto projeto coletivo.

Nesse sentido, é necessário mencionar que em 2017, com a mudança de governo municipal, começou a delinear-se uma nova Política Pública de Educação na RME/POA. Dentre as mudanças, destacamos a redução do tempo de permanência dos estudantes nas escolas e a retirada do tempo das reuniões pedagógicas semanais, planejamento coletivo e tempo de formação dos docentes ${ }^{10}$. Essa nova organização que muda as rotinas do cotidiano pedagógico das escolas da RME/POA sem dialogar com as comunidades inclui, ainda, a redução dos períodos de aula dos estudantes de 50 para 45 minutos e do recreio de 20 para 15 minutos $^{11}$, a diminuição da alimentação escolar, além de não suprir de Recursos Humanos as inúmeras deficiências da RME/POA.

Essas mudanças ocorridas no contexto educacional da RME/POA têm impactado os docentes, ocasionando profundas críticas às mudanças determinadas pelo Governo Municipal.

Ao abordar o tema Políticas Públicas de Educação na perspectiva da Educação Física, Oliveira (1994, p. 105) diz que "apesar de educação e política terem suas especificidades, todo ato político pressupõe uma dimensão pedagógica, da mesma forma que toda pedagogia deixa transparecer uma dimensão política". Nesse sentido, o trabalho docente jamais será neutro diante do mundo ${ }^{12}$, significando que o docente deve ao mesmo tempo se posicionar politicamente e pensar a educação como ato político.

8 Denominação que o Projeto Educacional da Administração Popular recebeu, a partir de 1993. Esse projeto propôs uma profunda reestruturação na organização do tempo pedagógico dos estudantes durante sua permanência na escola, transformando o modelo de currículo em séries anuais para uma estrutura curricular em Ciclos de Formação.

9 Em 2005 uma nova coalizão política, eleita em oposição à anterior, assume a Administração Municipal de Porto Alegre.

10 O novo governo publica em 21 de fevereiro de 2017 o Decreto 19.685, que revoga o Decreto 14.521, de 1ㅇde janeiro de 2004 . O Decreto 14.521, de 2004, prevê horas de planejamento pedagógico (preparação de aula, correção de trabalhos) e de estudos individuais. 0 decreto também prevê uma reunião pedagógica semanal com todos os professores de cada escola.

11 A Portaria 135/2017 (publicada no Diário Oficial do Município em 24 de fevereiro de 2017) estabelece diretriz para o Calendário Escolar da Rede Municipal de Ensino de Porto Alegre durante o ano letivo de 2017.

12 Para FREIRE (1996; 1998) é impossível alguém estar no mundo, com os outros, de forma neutra. 
É necessário mencionar, ainda, que a Educação Física está inserida na "área das linguagens", especialmente da cultura e das linguagens corporais. Assim, vale destacar que a Educação Física é um componente curricular cuja responsabilidade é tratar das práticas corporais na escola como "fenômeno cultural dinâmico, diversificado, pluridimensional, singular e contraditório" (BRASIL, 2017, p. 171), garantindo aos estudantes a construção de um conjunto de conhecimentos necessários à formação integral do cidadão. Portanto, a Educação Física se caracteriza como um componente curricular singular, sendo a única que busca promover diretamente as múltiplas linguagens da cultura corporal de movimento.

\section{METODOLOGIA}

Considerando que o lócus da pesquisa foi o contexto escolar, os princípios de uma etnografia educativa, pelas suas características, se constituíram na decisão metodológica que possibilitou compreender de que modo as Políticas Públicas de Educação interferem no trabalho docente da Educação Física Escolar, a partir do cotidiano desses docentes na escola.

A etnografia educativa tem sido designada por etnografia crítica (MOLINA NETO, 2010), pois apresenta potencialidades para estudar em profundidade o cotidiano pedagógico dos docentes no contexto educativo.

Nesse sentido, Quantz (1992) contribui quando afirma que a base teórica da etnografia é a Teoria Crítica. Para esse autor, a etnografia crítica permite ir além de uma simples descrição, pois possibilita uma reflexão crítica e dialógica mais ampla em relação ao objeto e ao contexto de estudo. 0 exercício de pensar criticamente as informações produzidas no processo de estudo, a meu ver, pode contribuir para responder e compreender o problema de pesquisa.

Destaco que, de acordo com Quantz (1992), a etnografia crítica é um modo de pesquisar que propicia a priorização da cultura e das experiências vividas no sentido de aprender com os outros.

É necessário mencionar que a etnografia crítica possibilita reconhecer a voz dos colaboradores da pesquisa, situando-os como protagonistas de sua história pessoal e social e promovendo sua condição de sujeitos da pesquisa, muitas vezes negada na perspectiva positivista, que acaba colocando pesquisadores e colaboradores em lados distintos. Nesse sentido, os relatos dos docentes que ilustram nossa análise são consideradas vozes de um coletivo no contexto de uma rede de ensino.

No que se refere à escolha dos docentes colaboradores, levamos em consideração os seguintes critérios: ser docente da escola e ter no mínimo 20 horas semanais com regência de classe em Educação Física na escola pesquisada; ter disponibilidade, interesse e vontade de participar da pesquisa e, por fim, representar as seis fases e percurso de vida na docência, ou seja, o tempo de docência ${ }^{13}$. Esse critério foi pautado pela preocupação de integrar docentes com diferentes tempos de experiências e vivências.

As informações foram obtidas através das observações sistemáticas do cotidiano escolar registradas no diário de campo, questionário, análise de documentos oficiais e os disponibilizados pelas escolas, além das entrevistas semiestruturadas realizadas com oito docentes de Educação Física de duas escolas de ensino fundamental da RME/POA, ambas 
localizada na periferia da cidade de Porto Alegre/RS. O trabalho de campo iniciou em setembro de 2014 e findou em dezembro de 2015, totalizando um ano e quinze meses de visitas sistemáticas às escolas e de observação constante dos colaboradores.

Para compreender o tema de estudo, estruturamos o roteiro de entrevista em blocos temáticos. 0 bloco que privilegiou o tema deste artigo aborda as Políticas Públicas em Educação, contendo questões relacionadas ao "Plano Nacional de Educação e Plano Municipal de Educação", "influência das Políticas Públicas no trabalho docente" e "Programa Mais Educação/Cidade Escola".

O questionário como um dos instrumentos de obter informações teve o objetivo de qualificar as questões das entrevistas e aprofundar a compreensão do problema de pesquisa. O questionário foi composto por 13 questões, sendo 11 para caracterização do perfil sociodemográfico do docente colaborador e da sua relação com o campo em estudo e duas questões discursivas, em que os docentes expressaram livremente suas percepções a respeito do seu trabalho docente, suas experiências e as atuais Políticas Públicas em Educação na RME/POA.

Além disso, o questionário foi de suma importância, visto que os docentes de Educação Física revelaram o modo como percebem e articulam as suas experiências, o seu trabalho docente e as ações da Política Pública de Educação que vem sendo implementada pela Secretaria Municipal de Educação de Porto Alegre (SMED/POA).

Para que os objetivos do estudo fossem alcançados, procuramos articular as leituras e os autores que foram fundamentais neste trabalho com a pesquisa de campo. Realizamos a triangulação desde a fase de obtenção de informações até a análise destas através de diferentes procedimentos usados no trabalho de campo, tais como entrevistas, observações registradas no diário de campo, questionário, documentos e os referenciais bibliográficos consultados. A ideia é de que esse processo ajuda o investigador a lidar com as percepções e opiniões concebidas, evitando, desse modo, que, como pesquisadora, deixe-me levar pelas "impressões iniciais" (MOLINA NETO, 2010).

A análise das informações ocorreu simultaneamente ao processo de obtenção destas, pois, segundo autores como Bogdan e Biklen (1994) e Gómez, Flores e Jiménez (1996), a análise deve ocorrer durante todo o processo de pesquisa. Porém, a análise começou a ser sistematizada de fato na fase final do trabalho de campo, quando estava com o conjunto de entrevistas transcritas e validadas.

Para identificar as categorias de análise, realizamos uma leitura atenta das entrevistas, questionários, dos Projetos Políticos Pedagógicos das escolas, do Plano Municipal de Educação e das anotações no diário de campo, nas quais destacamos algumas informações que, nesse momento, consideramos significativas para compreender o problema de pesquisa. O procedimento seguinte se constituiu em classificar e agrupar, por proximidade temática, as unidades de significado.

A fim de cumprir com os cuidados éticos necessários para toda a pesquisa com seres humanos, o presente estudo foi submetido à apreciação pelo Comitê de Ética em Pesquisa da Universidade Federal do Rio Grande do Sul, após registro na Plataforma Brasil, sendo aprovado em 2014 e executado de acordo com a Resolução do CNS-MS 466/12. Todos os sujeitos colaboradores participaram como voluntários da pesquisa, a partir da assinatura do 
Termo de Consentimento Livre e Esclarecido. Para garantir o sigilo das fontes de informações, os nomes de todos os sujeitos envolvidos na pesquisa foram substituídos por nomes fictícios.

\section{IMPACTOS DAS POLÍTICAS PÚBLICAS DE EDUCAÇÃO NA RME/POA: A PERCEPÇÃO DOS DOCENTES DE EDUCAÇÃO FÍSICA}

O PNE-2014/2024, que é uma política de Estado, repercute diretamente na Política Pública de Educação dos municípios, influenciando o cotidiano pedagógico das escolas e o trabalho docente, inclusive, direciona as metas dos Planos Municipais de Educação. Entendemos que há uma relação de interdependência entre os PME e o PNE, visto que os objetivos e metas do plano nacional são traduzidos para a realidade local, ou seja, é necessário adequar às particularidades e demandas municipais. Sendo assim, a análise do impacto das Políticas Públicas de Educação na RME/POA se faz necessária, tendo em vista a repercussão das atuais mudanças determinadas pela Secretaria Municipal de Educação.

Para analisar como os docentes de Educação Física experienciam, em seu trabalho docente, no cotidiano das escolas, as atuais Políticas Públicas de Educação na RME/POA, tomamos a decisão de elaborar, além das entrevistas, um questionário destinado a todo 0 professorado da referida Rede. As entrevistas foram de grande valia para organizar 0 questionário. Vale destacar, novamente, que esse instrumento possibilitou obter informações significativas para responder à problemática central deste estudo, que poderão ser observadas no decorrer da análise deste texto.

O pouco entusiasmo dos docentes em dialogar criticamente sobre as Políticas Públicas de Educação pode ser percebido em alguns relatos que apresentamos a seguir.

\footnotetext{
Nos últimos tempos tenho me dedicado menos em discutir [...] as questões das políticas públicas. Tu acaba fazendo algumas escolhas. Agora o que eu percebo assim, quando começa se discutir políticas públicas quando elas aparecem, [...] a própria questão do PME, [...] eu participei da parte basicamente da escola, [...] até porque eu tinha outras demandas, eu tive que fazer escolhas, eu considero fundamental a questão das políticas públicas, porque é ali que se pensa também como que é a educação vai ter certos desdobramentos. [...]. Então, não estar acompanhando, não estar presente nisso, também te deixa refém daquilo que vai ser votado, que vai ser aprovado (Prof. Cleber, entrevista realizada em $13 / 07 / 2015)^{14}$.
}

O relato ora transcrito apresenta um aspecto importante acerca das Políticas Públicas de Educação e o trabalho docente, na medida em que as demandas do cotidiano impulsionaram a tomar a decisão de não participar e se envolver no processo de discussão do coletivo docente.

A docente Luana tem percepção semelhante à de Cleber, revelando também que se sente sobrecarregada com a intensificação do trabalho docente. Hargreaves (1996) contribui para entender o contexto de trabalho do professorado quando discute como a intensificação do trabalho tem contribuído para que alguns docentes se afastem de decisões de relevância para o cotidiano pedagógico no contexto escolar. $O$ relato da docente Luana também é significativo nesse sentido: "na verdade, assim, [...] tem muitas coisas que eu desconheço, às vezes, é por falta de tempo, às vezes é por falta de interesse, porque a nossa prática consome a gente" (Entrevista realizada em 27/10/2015). 
O relato ora transcrito indica que as condições objetivas vividas no cotidiano pedagógico pela docente Luana e pelo docente Cleber têm influenciado o afastamento dos debates relacionados às Políticas Públicas de Educação. A falta de tempo, consequência da intensificação do trabalho docente, tem levado os professores, de acordo com Molina Neto e Molina (2013, p. 234), "ao individualismo".

Nessa direção, o relato da docente Samyra revela que seu trabalho docente no cotidiano pedagógico da escola se constitui no isolamento. Retomamos o entendimento de Hargreaves (1996) de que a intensificação do trabalho docente pode gerar um isolamento dos docentes. "Eu vivo no meu mundo [...]. Eu vou ser bem sincera, nem sei se eu quero me envolver mais com elas [Política Educacional]. [...] Eu vivo numa ilha. [...] Cada professor chega na escola, [...] e fica no seu mundo e, ninguém cobra ninguém" (Entrevista realizada em 24/06/2015).

Esse isolamento pedagógico revelado no relato acima indica que a docente procura, intencionalmente, nas experiências individuais, uma saída para superar as contradições e enfrentar os desafios do seu trabalho no cotidiano escolar.

Para a colaboradora Liana, a precarização do ensino e do trabalho docente está no centro das Políticas Públicas de Educação.

Eu acho que essas políticas atuais, elas estão vindo assim, eu acho para dificultar mais e precarizar mais o ensino público. Eu acho que eles estão tentando tirar direitos que foram adquiridos a custo de muita luta, que beneficiavam muitos alunos e as escolas, eu acho que tão tentando enxugar mais e tirar os direitos (Prof̣̂. Liana, entrevista realizada em 28/08/2015).

O relato ora transcrito revela que a precarização é mais visível à medida que tem como propósito reduzir os recursos humanos, impossibilitando, assim, a melhoria do processo pedagógico da escola e, consequentemente, o trabalho docente. Essa redução de recursos humanos tem forçado os docentes a assumirem diferentes funções na escola, por exemplo, realizarem mensalmente o registro online da frequência dos estudantes, no Sistema de Informações Educacionais (SIE) ${ }^{15}$ da Companhia de Processamento de Dados do Município de Porto Alegre.

A colaboradora Ellen destaca o envolvimento do coletivo docente da escola nas discussões do Plano Municipal de Educação, criticando a forma como foram aproveitadas as propostas encaminhadas pelos docentes nas plenárias do Congresso Municipal de Educação.

Eu faço muita relação, e uma visão dessas coisas é um sucateamento total da educação [...]. Eu fiquei meio frustrada com esse trabalho, eu acho que quase toda a rede, porque nós trabalhamos num sábado inteiro aqui, dois sábados, foram oito horas que nós trabalhamos, oito horas aqui dentro da escola, saíram os delegados que foram para lá [Congresso Municipal de Educação] nos representar e defender as emendas. [...] Na verdade foi o que eles queriam e, o que eu vejo em educação que a maioria das coisas são feitas assim, não só lá, como por parte, às vezes, da nossa mantenedora, da SMED, que faz, faz a reunião para que seja no final definida aquilo que quer e, como já está se usando aqui dentro da escola, também. [...] Não foi levado em consideração tantos manifestos, tantas coisas que se pregou e que se pediu e que, eu acho que isso é fechar os olhos para o que se vive ou, no mundo atual (Prof ${ }^{a}$. Ellen, entrevista realizada em 19/11/2015).

15 É um instrumento que informa no sistema a presença dos estudantes para o acompanhamento da frequência escolar do Programa Bolsa Família. O Bolsa Família é um programa Federal de transferência direta de renda, com condicionalidades, que beneficia famílias em situação de pobreza. Abrange crianças e adolescentes na faixa etária de seis a 15 anos, com frequência escolar mínima de $85 \%$ da carga horária mensal. 
Pude observar no Pré-Congresso e no Congresso Municipal de Educação que

Houve a tentativa de contemplar as contribuições encaminhadas pelo coletivo docente da EMEF Gama, que por um equívoco não foi incluído no texto-base para a análise da comunidade educacional do município, porém, a comissão que coordenava o processo de discussão, fundamentado pelas normas do Congresso, não permitiu a apreciação das propostas da referida escola (Diário de Campo n² 26, 28/03/2015).

No relato, a docente Ellen tece críticas contundentes a respeito da Coordenação da Comissão Municipal Institucional da SMED/POA desconsiderar as experiências daqueles que fazem o cotidiano pedagógico das escolas, ou seja, os docentes.

$O$ relato da docente Ellen evidencia, ainda, que prevaleceu o interesse dos gestores da SMED/POA na elaboração do Plano Municipal de Educação. Diante dessa circunstância, é necessário considerar que a elaboração das Políticas Públicas é um espaço de tensões, conflitos e lutas, pois os grupos que estão no momento da construção dos textos procuram legitimar as suas ideias, interesses e ideologias. Nesse aspecto, Mainardes (2006, p. 51) contribuiu ao esclarecer que é no "contexto de influência" que "grupos de interesse disputam para influenciar a definição das finalidades sociais da educação e do que significa ser educado". Segundo esse autor, o "contexto de influência permeia tanto os processos macropolíticos ocorridos em escala nacional, como os processos intermediários, bem como os microprocessos locais e intraescolares. $\mathrm{O}$ autor explicita ainda que,

[...] os textos são produtos de múltiplas influências e agendas e sua formulação envolve intenções e negociação dentro do Estado e dentro do processo de formulação da política. Nesse processo, apenas algumas influências e agendas são reconhecidas como legítimas e apenas algumas vozes são ouvidas (MAINARDES, 2006, p. 53).

É possível perceber, nesse sentido, que a influência dos docentes na construção do Plano Municipal de Educação foi limitada, pois sua participação nessa Política Pública de Educação está mais presente durante a implementação da proposta no "contexto da prática" (BALL, 2001; MAINARDES, 2006), ou seja, no momento que o trabalho docente se materializa no cotidiano pedagógico das escolas.

Na percepção do docente Gabriel, há necessidade de mudanças nas Políticas Públicas em Educação visando à formação de sujeitos críticos capazes de lutar por melhores condições de vida. Esse docente, ao revelar a substituição de professores por oficineiros ${ }^{16}$, tem percepção semelhante à de Liana a respeito da precarização do ensino e do trabalho docente, anteriormente mencionado. É o que revela o depoimento a seguir:

O que nós temos que fazer a médio e longo prazo está muito claro e todo mundo sabe o que tem que fazer, [...] eles não fazem por dois motivos, primeiro porque não tem interesse, porque o povo mais informado, mais culto, mais problema vai dar para os políticos. Então a segunda coisa, eles querem manter uma escola num padrão assistencialista, [...] em vez de ser um local onde tenho que ir para vivenciar, para aprender, para se divertir, para ter novas experiências, e sim para ser um depósito de gente, está muito claro, são poucas escolas que conseguem romper com essa questão, onde tem um monte de oficineiros, um monte de dinheiro para outras coisas, que na verdade era para ter professores, era para ter um $\mathrm{RH}$ maior, era para ter um espaço físico mais adequado (Prof. Gabriel, entrevista realizada em 25/09/2015).

16 Denominação utilizada para designar os trabalhadores que desenvolvem o trabalho docente no contexto do Programa Mais Educação/ Cidade Escola da RME/POA e que não pertencem ao quadro de docentes efetivos da escola. 
É possível identificar no relato ora transcrito que o docente acredita em uma escola com um ambiente agradável que possibilite aos estudantes vivenciar novas experiências, favorecendo, assim, o processo de ensino e aprendizagem. Para esse docente, algumas escolas têm se colocado a tarefa de apresentar alternativas para superar esta situação no próprio espaço escolar. Nesse sentido, Ball (2001) e Mainardes (2006) contribuem quando afirmam que no contexto da prática as Políticas Públicas estão sujeitas a interpretações, podendo representar mudanças na política original. É necessário considerar que as histórias de vida e experiências dos docentes envolvidos no cotidiano pedagógico das escolas exercem influência no processo de implantação de uma Política Pública de Educação, ou seja, no contexto da prática é que as políticas podem ser reinterpretadas e ressignificadas de modo diferente daquelas pretendidas pelos gestores que, em alguns casos, desconhecem o contexto do trabalho docente.

É necessário observar que os docentes, em seus relatos acima transcritos, convergem quando a temática é Políticas Públicas de Educação. Os depoimentos indicam que alguns docentes não se sentem envolvidos em algumas discussões, demonstrando desinteresse quando 0 assunto está relacionado às Políticas Públicas de Educação. Pensamos que a forma como o processo de elaboração de algumas Políticas Educacionais vem sendo conduzido, desprezando as experiências e a participação efetiva do professorado, pode ter influenciado 0 desinteresse e/ou distanciamento dos docentes colaboradores da pesquisa das discussões relacionadas a Políticas Públicas de Educação. Esse desinteresse e distanciamento, a nosso ver, não revela necessariamente omissão ou ausência de criticidade dos docentes, mas uma posição diante das condições materiais e objetivas às quais está submetido o professorado de Educação Física. Para Oliveira, (1994, p. 105), "nossas ações representam uma determinada postura política que deve ser compreendida em todo o seu comprometimento".

\section{CONSIDERAÇÕES TRANSITÓRIAS}

O estudo evidenciou que a influência dos docentes na construção da Política Pública de Educação - materializada em seus diferentes planos e programas - é limitada, pois sua participação está mais presente durante a implementação das propostas no "contexto da prática" (BALL, 2001; MAINARDES, 2006), ou seja, no momento que o trabalho docente se materializa no cotidiano pedagógico das escolas.

O desenvolvimento da pesquisa nos ofereceu a possibilidade de pensar que o modo como o processo de elaboração das Políticas Públicas em Educação vem sendo conduzido, desprezando as experiências e a participação efetiva do professorado, pode influenciar na concretização das propostas no contexto da prática, visto que, a partir das interações dos docentes, que atuam no cotidiano pedagógico das escolas, com as políticas podem reinterpretálas e ressignificá-las de forma diferente daquelas pretendidas pelos especialistas.

É possível pensar que uma Política Pública de Educação, que reúne diversos programas e planos, tem que ter legitimidade para alcançar o comprometimento dos docentes no trabalho e a desejada qualidade educacional e social. Entendemos que a Política Pública de Educação necessita ser submetida a um amplo debate que incorpore a riqueza das diferentes visões de mundo e experiências que sociedade tem sobre o contexto social em que as escolas estão inseridas. 
Entre outras contribuições, o estudo que realizamos reforça que é necessário elaborar Políticas Públicas em Educação que tenham como princípio a participação dos docentes na elaboração e nas tomadas de decisões.

Acreditamos que o maior desafio das Políticas Públicas de Educação é sua concretização, considerando que a participação, aceitação e o apoio efetivo dos docentes são parte fundamental para implantação das mudanças educacionais.

Para finalizar esta análise, caberia, como síntese, destacar que as experiências vivenciadas no trabalho docente e no cotidiano pedagógico das escolas podem ser pensadas enquanto manifestações concretas de uma Política Pública de Educação que é interpretada e recriada pelo professorado de Educação Física no contexto escolar.

\section{REFERÊNCIAS}

APPLE, Michael; AU, Wayne; GANDIN, Luís A. Educação crítica: análise internacional. Porto Alegre: Artmed, 2011.

AZEVEDO, José C.; RODRIGUES, Carolina C.; CURÇO, Sumaia F. Escola cidadã: Políticas e práticas inclusivas. Arquivos Analíticos de Políticas Educativas, v. 18, n. 2, jan. 2010. Disponível em: http://epaa.asu.edu/epaa/v18n2. Acesso em: 27 ago. 2018.

BALL, Stephen J. Diretrizes Políticas Globais e Relações Políticas Locais em Educação. Currículo sem Fronteiras, v. 1, n. 2, p. 99-116, jul./dez. 2001.

BOGDAN, Robert C.; BIKLEN, Sari K. Investigação Qualitativa em Educação: uma introdução à teoria e aos métodos. Porto: Porto Editora, 1994.

BRASIL. Lei n. ${ }^{\circ}$ 13.005, de 25 de junho de 2014. Aprova o Plano Nacional de Educação e dá outras providências. Diário Oficial da União, Brasília, DF, 26 jun. 2014. Disponível em: http:// www.planalto.gov.br/CCIVIL 03/ Ato2011-2014/2014/Lei/L13005.htm. Acesso em: 26 jun. 2017.

BRASIL. Livro do Plano de Desenvolvimento da Educação (PDE). 2008. Disponível em: http://portal.mec.gov.br/arquivos/pdf/livromiolov4.pdf. Acesso em: 10 mar. 2019.

BRASIL. Ministério da Educação e Cultura. Base Nacional Comum Curricular. Brasília, 2017.

DAY, Christopher; GU, Qing. Professores: vidas nuevas, verdades antigas: uma influencia decisiva em la vida de los alumnos. Madrid: Narcea, 2012.

FREIRE, Paulo. Educação e Participação Comunitária. In: CASTELLS, Manuel et al. Novas Perspectivas Críticas em Educação. Porto Alegre: Artes Médicas, 1996. p. 53-61.

FREIRE, Paulo. Pedagogia da Autonomia: saberes necessários à prática educativa. 8. ed. Rio de Janeiro: Paz e Terra, 1998.

GÓMEZ, Gregório R.; FLORES, Javier Gil; JIMÉNEZ, Eduardo G. Metodologia de la Investigación Cualitativa. Barcelona: Aljibe, 1996.

HARGREAVES, Andy. Professorado, cultura y postmodernidad: cambian los tiempos, cambia el professorado. Madrid: Morata, 1996. 
MAINARDES, Jefferson. Abordagem do ciclo de políticas: uma contribuição para a análise de políticas educacionais. Educação \& Sociedade, v. 27, n. 94, p. 47-69, jan./abr. 2006. Disponível em: www.scielo.br/pdf/es/v27n94/a03v27n94.pdf. Acesso em: 05 jul. 2018.

MOLINA NETO, Vicente. Etnografia: uma opção metodológica para alguns problemas de investigação no âmbito da Educação Física. In: MOLINA NETO, Vicente; TRIVIÑOS, Augusto N. S. (orgs.). A Pesquisa Qualitativa na Educação Física: alternativas metodológicas. 3.ed. Porto Alegre: Sulina, 2010. p. 113-145.

MOLINA NETO, Vicente; MOLINA, Rosane. O que os professores de Educação física têm a dizer sobre os ciclos de formação. In: MOLL, Jaqueline. (org.) Os tempos da vida nos tempos da escola: construindo possibilidades. 2. ed. Porto Alegre: Penso, 2013. p. 229-237.

OLIVEIRA. Vitor M. Consenso e Conflito: da Educação Física brasileira. Campinas: Papirus, 1994.

PREFEITURA MUNICIPAL DE PORTO ALEGRE. Lei 11.858/2015 Plano Municipal de Educação. Porto Alegre: PMPA, 2015.

PREFEITURA MUNICIPAL DE PORTO ALEGRE. SMED. Ciclos de Formação: Proposta Político Pedagógica da Escola Cidadã. Caderno Pedagógico n 9. 3. ed. Porto Alegre, 2003.

PREFEITURA MUNICIPAL DE PORTO ALEGRE. SMED. Políticas Pedagógicas: documento orientador para o Ensino Fundamental. Porto Alegre, 2015.

QUANTZ, Richard A. On critical ethnography. In: LECOMPTE, Margareth D. (Eds). The handbook of qualitative research in education. California: Academic, 1992. p. 447-505. 